\title{
Model Pendidikan Kecerdasan Spiritual Anak Balita Melalui Pemanfaatan Waktu Luang Ibu Rumah Tangga
}

\author{
Oleh Wahyudi Siswanto
}

\begin{abstract}
Abstrak
Banyak orang sukses yang mengalami krisis spiritual. Itulah sebabnya, orang ingin mengetahui sebab penyakit spiritual ini. Tahun 2000 orang mengungkapkan adanya kecerdasan spiritual. Mereka percaya bahwa inilah kecerdasan tertinggi. Para top eksekutif sepakat bahwa spiritual terbukti mampu membawa seseorang menuju tangga kesuksesan dan berperan besar dalam menciptakan mereka menjadi seorang powerful leader. Kedudukan ibu rumah tangga begitu penting di dalam agama Islam. Di antara waktu luang yang dimiliki ibu rumah tangga, akan bermanfaat bila digunakan untuk mendidik balitanya. Salah satu yang bisa dididikkan adalah kecedasan spiritual. Hal ini bisa dilakukan melalui (a) contoh perbuatan, (b) nasihat, (c) permainan, (d) teka-teki, (e) cerita, (f) lagu, (g) pembiasaan tingkah laku, dan (h) pembiasaan perkataan.
\end{abstract}

Kata kunci: kecerdasan spiritual, ibu rumah tangga, balita

Allah telah memberi kepada kaum ibu kedudukan yang luar biasa. Allah juga telah mengangkat derajat kaum ibu begitu tinggi. Bahkan, sorga terletak di telapak kaki ibu.

Jihat merupakan jalan yang dituntut di dalam agama Islam. Bagi yang meninggal dunia di jalan ini, maka ia masuk surga tanpa dihisap. Allah memberikan kepada Ibu jalan berjihat. Kaum ibu bisa berjihat di dalam 
rumah. Keringat ibu-ibu saat mengurusi putra-putri dan suami adalah ladang ibu untuk mencari pahala yang melimpah.

Di antara 'pekerjaan' rutinnya, ibu rumah tangga terkadang masih mempunyai waktu luang. Sebagian waktu luang itu dimanfaatkan untuk mengurus dan memanjakan diri sendiri.Tidak masalah. Bukankah kita juga harus mengurus diri sendiri. Yang sangat disayangkan, bila waktu luang itu dibuang percuma, apalagi dimanfaatkan untuk sesuatu yang mengundang dosa.

Akan lebih baik bila waktu luang itu kita manfaatkan untuk mendidik balita kita. Bukankah kesempatan tidak pernah datang dua kali? Bahkan, Allah yang Mahatahu sudah bersumpah, bahwa sesungguhnya manusia itu benar-benar dalam kerugian, kecuali orang-orang yang beriman dan mengerjakan amal saleh dan nasehat menasehati supaya mentaati kebenaran dan nasehat menasehati supaya menetapi kesabaran (AlAshr:1-3).

Kita sadar bahwa waktu tidak bisa kembali. Oleh karena itu, gunakanlah detik demi detik untuk mendidik anak. Bukankah mendidik anak adalah ladang orang tua untuk mencari rido Allah?

Mari kita didik anak kita selagi kita bisa. Ingat lima perkara sebelum lima perkara: sehat sebelum sakit; muda sebelum tua; kaya sebelum miskin; lapang sebelum sempit; hidup sebelum mati. Apa yang bisa kita belajarkan dari putra-putri kita? Salah satunya adalah kecerdasan spiritual.

\section{Kecerdasan Spiritual}

Daniel Goleman memperkenalkan EQ (Emotional Intelligence) dengan menunjukkan bukti empiris dari penelitiannya bahwa orang-orang yang IQ tinggi tidak menjamin untuk sukses. Sebaliknya, orang yang memiliki EQ, banyak yang menempati posisi kunci di dunia eksekutif (Tasmara, 2001; Satiadarma dan Waruwu, 2003). 
Apakah orang yang sudah sukses di dunia eksekutif memang benarbenar bahagia? Ternyata, banyak orang yang merasa sudah mencapai citacita atau puncak kesuksesan baik karier maupun materi, tetapi merasakan sesuatu yang "hampa dan kosong".

Umumnya, mereka baru menyadari bahwa mereka telah menaiki tangga yang salah, justru setelah mencapai puncak tertinggi anak tangga kariernya. Ternyata pada akhirnya, uang, harta, kehormatan, dan kedudukan bukanlah "sesuatu" yang mereka cari selama ini (Agustian, Ary Ginanjar. 2004: 11).

Posisi sukses ini ternyata dianggap semu. Orang banyak mengalami krisis. Krisis ini bersifat global. Krisis global yang kompleks dan multidimensional ini, sudah merambah setiap sudut kehidupan kita mulai dari kesehatan, mata pencaharian, kualitas lingkungan, hubungan sosial, ekonomi, teknologi, politik, dan bahkan merasuk ke dalam krisis moral, intelektual, dan krisis spiritual. Fenomena krisis manusia tersebut sebenarnya berasal dan bermuara pada "krisis spiritual" yang bercokol dalam diri kita. Hipotesisnya adalah bahwa nilai-nilai moral itu merupakan buah dari agama. Logikanya, bila merebak krisis moral, berarti itulah buah dari krisis spiritual-keagamaan dalam diri kita. Kita sudah terjangkit penyakit spiritual atau krisis spiritual. Carl Gustav Jung, menyebut krisis spiritual sebagai penyakit eksistensial (existential illness), di mana eksistensi diri kita mengalami penyakit alienasi (keterasingan diri), baik dari diri sendiri, lingkungan sosial, maupun teralienasi dari Tuhannya.

Kondisi psikologis seperti itu dirumuskan oleh Zohar dan Marshall sebagai bentuk keterputusan diri, baik dari diri sendiri (cut off from myself), dari orang lain di sekelilingnya (from others around me), dan bahkan dari Tuhannya (from God) (Sukidi, 2004).

Orang ingin mengetahui jawaban sebab penyakit spiritual itu. Tahun 2000 orang mengungkapkan adanya kecerdasan spiritual. Kecerdasan spiritual (SQ), yang merupakan temuan terkini secara ilmiah, pertama kali digagas oleh Danah Zolhar dan lan Marshall, masing-masing dari Harvard 
University dan Oxford University melalui riset yang sangat komprehensif. Pembuktian ilmiah tentang kecerdasan spiritual yang dipaparkan Zohar dan Marshall dalam SQ:, Spiritual Quotient, The Ultimate Intelligence (London, 2000). Dua di antaranya adalah: Pertama, riset ahli psikologi/syaraf, Michael Persinger pada awal tahun 1990-an, dan lebih mutakhir lagi tahun 1997 oleh ahli syaraf V.S. Rarnachandran dan timnya dari California University, yang menemukan eksistensi God-Spot dalam otak manusia. Ini sudah built-in sebagai pusat spiritual (spiritual center) yang terletak di antara jaringan syaraf dan otak.

Bukti kedua adalah riset ahli syaraf Austria, Wolf Singer pada era 1990-an atas The Binding Problem, yang menunjukkan ada proses syaraf dalam otak manusia yang terkonsentrasi pada usaha yang mempersatukan dan memberi makna dalam pengalaman hidup kita. Suatu jaringan syaraf yang secara literal "mengikat" pengalaman kita secara bersama untuk "hidup lebih bermakna". Pada God-Spot inilah sebenarnya terdapat fitrah manusia yang terdalam (Agustian,2005)

Secara terminologi, kecerdasan spiritual merupakan kecerdasan pokok yang dengannya dapat memecahkan masalah-masalah makna dan nilai, menempatkan tindakan atau suatu jalan hidup dalam konteks yang lebih luas, kaya, dan bermakna. (Zohar dan Marshall, 2002). Kecerdasan spiritual lebih merupakan sebuah konsep yang berhubungan dengan bagaimana seseorang cerdas dalam mengelola dan mendayagunakan makna-makna, nilai-nilai, dan kualitas-kualitas kehidupan spiritualnya. Kehidupan spiritual meliputi hasrat untuk bermakna (the will to meaning) yang memotivasi kehidupan seseorang untuk senantiasa mencari makna hidup (the meaning of life) dan mendambakan hidup bermakna (the meaningful life) (Mujib dan Mudzakir, 2001:324).

Kecerdasan Spiritual adalah kemampuan seseorang yang memiliki kecakapan transenden, kesadaran yang tinggi untuk menjalani kehidupan, menggunakan sumber-sumber spiritual untuk memecahkan permasalahan hidup, dan berbudi luhur. la mampu berhubungan dengan baik dengan Tuhan, manusia, alam, dan dirinya sendiri. 
Para top Eksekutif sepakat dan setuju bahwa spiritual terbukti mampu membawa seseorang menuju tangga kesuksesan dan berperan besar dalam menciptakan mereka menjadi seorang powerful leader. (Agustian, Ary Ginanjar. 2004:5)

\section{Model Pendidikan Spiritual Balita}

Pendidikan spiritual bagi balita melalui pemanfaatan waktu luang ibu rumah tangga bisa dilakukan dengan berbagai model. Pendidikan ini bisa dilakukan dengan (a) contoh perbuatan, (b) nasihat, (c) permainan, (d) tekateki, (e) cerita, ( $f$ ) lagu, (g) pembiasaan tingkah laku, dan (h) pembiasaan perkataan. Berikut ini akan diberikan contoh saru per satu.

Kecerdasan apa saja yang bisa dikembangkan pada diri anak balita? Hal yang bisa dikembangkan, antara lain, adalah cinta kasih, kejujuran, kecerdasan, keadilan, bekerja sama, perhatian, mandiri, percaya diri, atau dermawan, baik dalam hubungannya dengan Tuhan, diri sendiri, sesama manusia, maupun alam sekitar. Dalam tulisan ini akan diberikan salah satu model pendidikan, yaitu pendidikan cinta dan kasih sayang.

Pendidikan cinta dan kasih sayang adalah pendidikan yang kepada anak kita untuk menumbuhkan perasaan kasih dan sayang diri anak kepada Tuhan, diri sendiri, orang lain, hewan, tumbuhan, dan kepada alam sekitar. Pendidikan ini harus kita berikan dengan perasaan kasih dan sayang kepada anak.

\section{a. Model Contoh Perbuatan}

Apa yang bisa lbu contohkan kepada anak tentang cinta dan kasih sayang? Contoh merupakan cara yang sesuai untuk menanamkan rasa cinta dan kasih anak. Ibu bisa melakukan hal di bawah ini.

(1) Biasakan membelai rambut atau kepala anak, sambil doakan agar ia menjadi anak yang soleh atau solehah. 


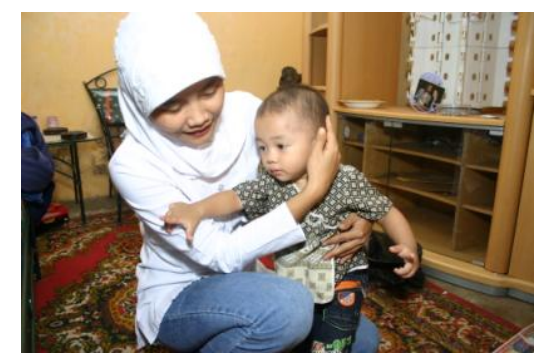

(2) Peluklah putra atau putri Ibu pada saat yang tepat. Berapa banyak di antara kita yang tidak bisa memeluk anak kita karena anak kita telah beranjak dewasa.

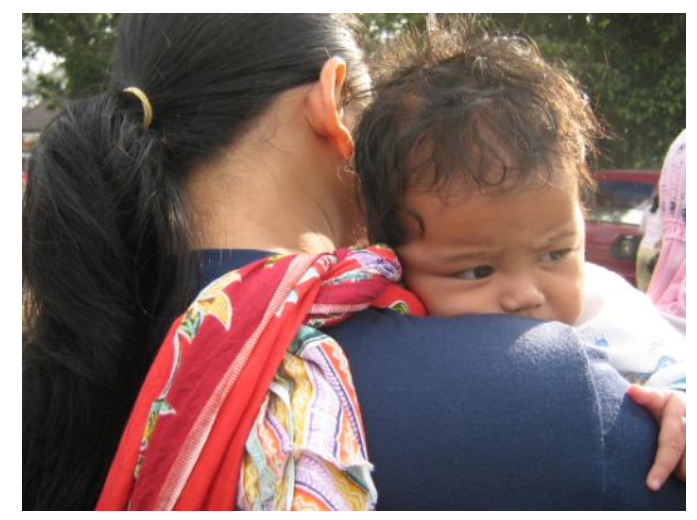

(3) Biasakan mencium anak. Bersyukurlah lbu, karena masih bisa menciumnya. Jangan lupa mendoakan anak lbu pada saat menciumnya.

(4) Jangan sakiti dia dengan memukul, mencubit, menampar apalagi tanpa alasan yang kuat (hukuman harus mendidik dan tidak boleh membahayakan anak) 
(5) Ajaklah anak-anak untuk mencintai Allah dengan solat bersama

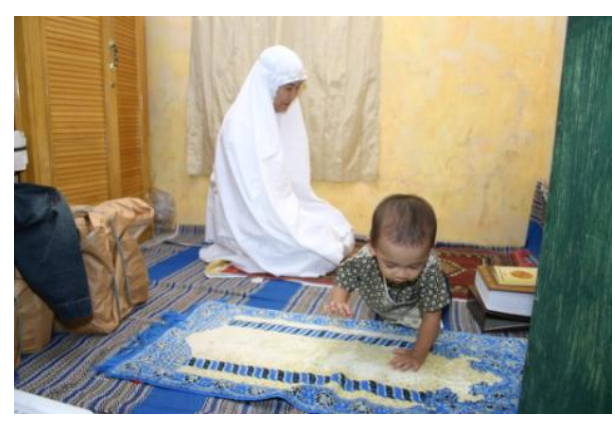

\section{b. Model Nasihat}

Anak seusia ini masih sulit untuk dinasihati. Oleh karena itu, jangan sering-sering menasihati, bila tidak perlu. Bila anak lbu melakukan hal-hal yang bertentangan dengan sifat atau perbuatan sayang, nasihatilah dia agar berbuat sayang.

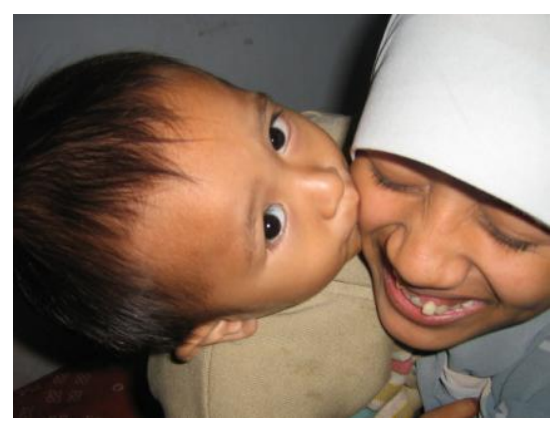

Apa yang bisa dinasihatkan kepada mereka tentang cinta dan kasih sayang? Ibu bisa menasihati anak dengan perkataan:

(1) Sayangilah Allah

(2) Sayangilah Rasulullah

(3) Sayangilah orang tua

(4) Sayangilah saudara 
(5) Sayangilah teman

(6) Sayangilah hewan

(7) Sayangilah tumbuhan

\section{c. Model Permainan}

Lewat bermain, kita bisa menanamkan sifat cinta dan kasih sayang kepada anak. Dengan cara ini, anak akan belajar tentang cinta dan sayang dengan perasaan senang. Berikut ini salah satu contoh permaianan itu.

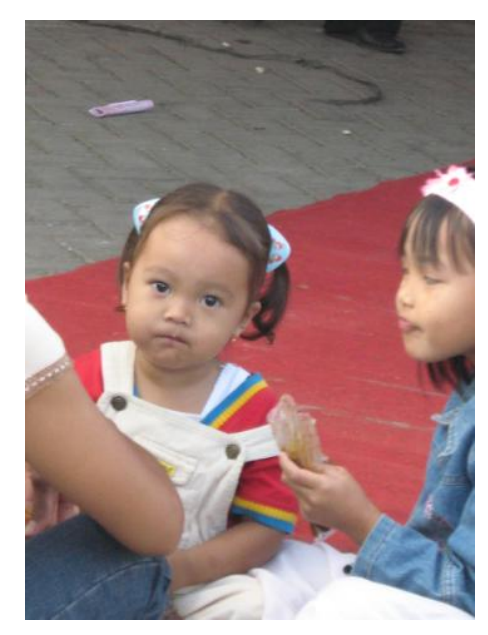

Mengganti kata

Anak diminta untuk mengucapkan kata "Aku sayang ayah". Bila Ibu menyebut "ibu", anak diminta untuk mengganti kata "ayah" dengan kata "ibu", sehingga ia harus mengucapkan "aku sayang ibu".

\begin{tabular}{|c|l|l|}
\hline No. & \multicolumn{1}{|c|}{ Ucapan lbu } & \multicolumn{1}{|c|}{ Ucapan Anak } \\
\hline 1. & $\begin{array}{l}\text { Aku sayang } \\
\text { Allah }\end{array}$ & Aku sayang Allah \\
\hline 2. & Muhammad & $\begin{array}{l}\text { Aku sayang } \\
\text { Muhammad }\end{array}$ \\
\hline
\end{tabular}




\begin{tabular}{|r|l|l|}
\hline 3. & Ibu & Aku sayang Ibu \\
\hline 4. & Ayah & Aku sayang Ayah \\
\hline 5. & Kakak & Aku sayang Kakak \\
\hline 6. & Adik & Aku sayang Adik \\
\hline 7. & Teman & Aku sayang teman \\
\hline 8. & Kucing & Aku sayang kucing \\
\hline 9. & Bunga & Aku sayang bunga \\
\hline
\end{tabular}

\section{d. Model Teka-Teki}

Teka-teki merupakan cara untuk mengajak anak berpikir kritis. Ajaklah anak lbu untuk menjawab pertanyaan-pertanyaan yang lbu berikan. Pertanyaan ini mengajak anak untuk mengetahui tentang Tuhan yang Maha Pengasih dan Maha Penyayang; orang-orang yang harus disayangi; atau cara menyayangi seseorang atau sesuatu.

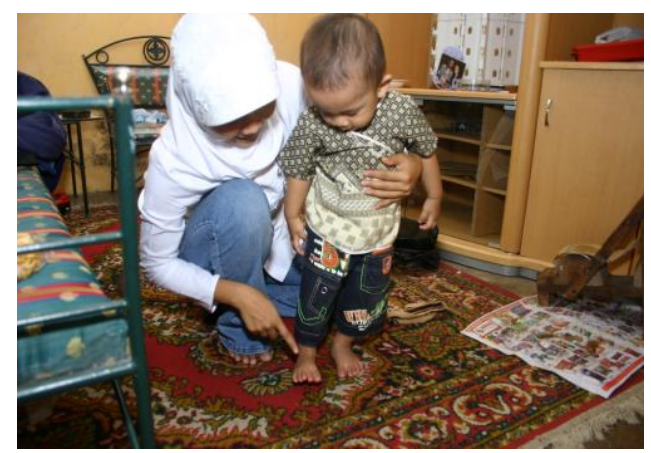

(1) Ini kaki. Siapa yang menciptakannya? (jawabnya: Allah)

(2) Siapakah yang menyayangi semua manusia? (jawabnya: Allah)

(3) Siapakah yang menyayangi semua tumbuhan? (jawabnya: Allah)

(4) Siapakah yang menyayangi semua hewan? (jawabnya: Allah)

(5) Apakah kamu sayang kepada lbu?

(6) Apakah kamu sayang kepada ayah? 
(7) Apakah kamu sayang kepada kakak?

(8) Apakah kamu sayang kepada bunga?

(9) Apakah kamu sayang kepada kucing?

\section{e. Model Cerita}

Cerita merupakan cara yang cocok untuk menanamkan rasa cinta dan kasih sayang kepada anak. Cerita ini bisa Ibu sampaikan menjelang tidur atau pada saat-saat sedang santai. Salah satu cerita itu adalah sebagai berikut.

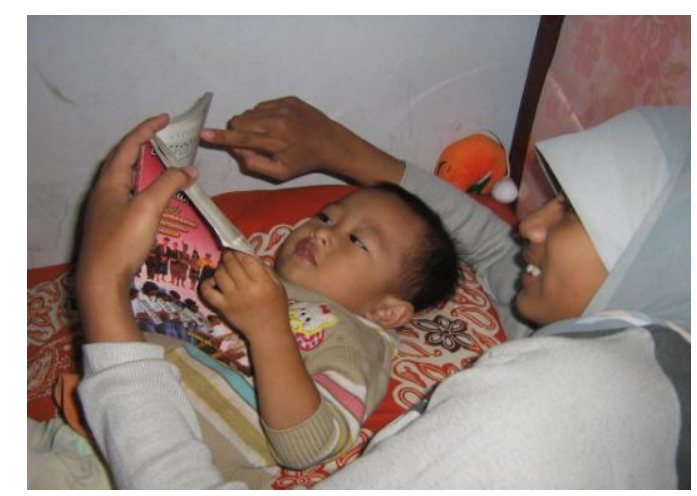

\section{Cinta Abdulla bin Umar kepada Pengemis}

Suatu hari Abdullah bin Umar sakit agak berat. Setelah beliau sembuh, beliau ingin makan ikan. Ketika itu ikan amat sulit didapati. Disuruhnya orang mencari ikan ke mana-mana. Setelah mendapatkan ikan, lalu dibawa pulang dan dimasak.

Ketika beliau akan makan ikan di pembaringan, di luar terdengar orang mengemis yang minta makan. Beliau berkata kepada pembantunya, "Bungkus ikan itu dengan rotinya sekalian dan berikan kepada orang yang minta makanan itu!"

Karena sulit mencarinya dan karena sayang kepada tuannya, ikan dan roti itu tidak diberikan kepada peminta-minta. Ikan itu disembunyikannya.

Sebagai gantinya, peminta-minta itu diberi uang satu dirham. Peminta-minta itu sangat gembira dan dengan muka girang dia pun keluar. 
Pembantu itu kembali lagi membawa ikan dan roti tadi kepada Abdullah bin Umar dan menceritakan perbuatannya, bahwa roti dan ikan itu telah digantinya dengan uang.

Abdullah bin Umar menyuruh pembatu itu menjemput pemintaminta tadi kembali dan menyerahkan ikan dan roti itu kepadanya. Dia mengorbankan keinginannya karena ada orang lain yang lebih membutuhkan makan.

\section{f. Model Lagu}

Bernyanyi merupakan kegemaran anak balita. Melalui lagu, Ibu bisa menyisipkan pendidikan rasa cinta dan sayang. Salah satu lagu itu adalah sebagai berikut.

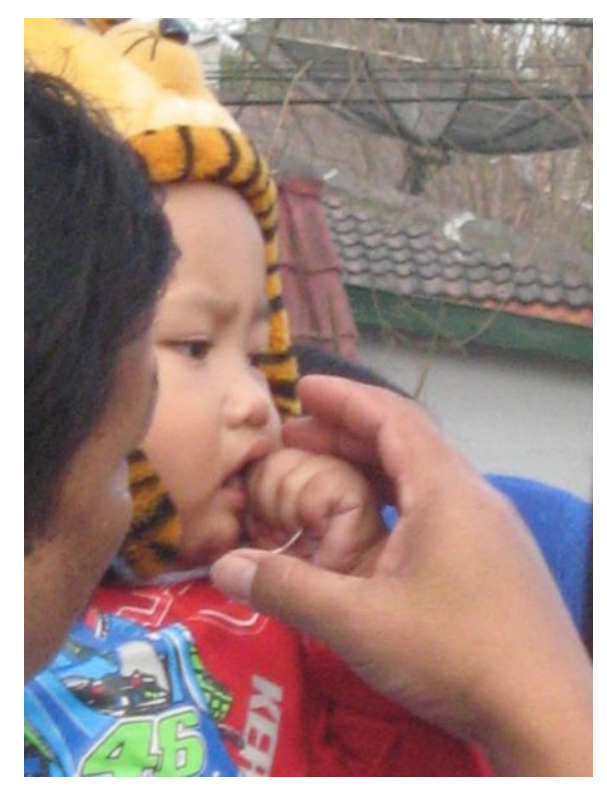

Satu satu aku sayang ibu Dua dua aku sayang ayah Tiga tiga sayang adik kakak Satu dua tiga sayang semuanya

Lagu tersebut bisa divariasi dengan lagu 
Satu satu aku sayang Allah

Dua dua aku sayang rasulullah

Tiga tiga sayang adik kakak

Satu dua tiga sayang semuanya

\section{g. Model Pembiasaan Tingkah Laku}

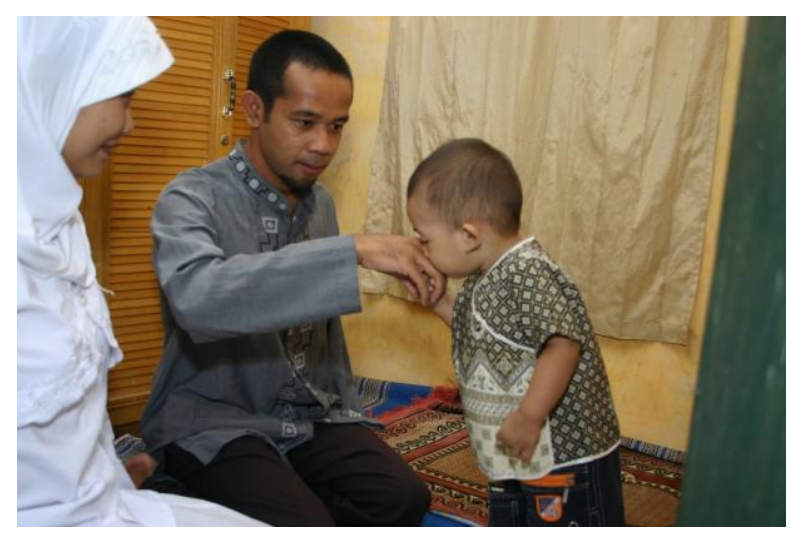

Ada pepatah, "Bisa ala biasa". Bila lbu ingin anak Ibu menjadi anak yang mempunyai sifat cinta dan kasih sayang, biasakan ia berbuat demikian. Pelatihan yang diberikan bisa berupa hal berikut.

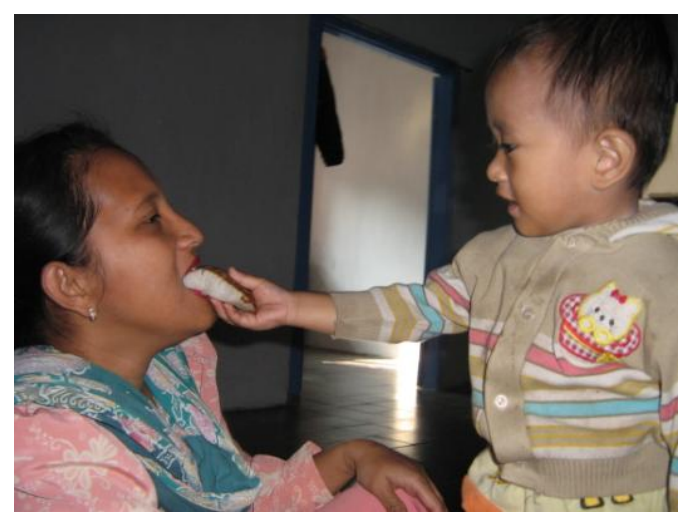

(1) Biasakan anak untuk memberi makanan kepada temannya.

(2) Biasakan anak untuk membagi makanan kepada temannya.

(3) Biasakan anak untuk membeli oleh-oleh untuk teman atau saudaranya.

(4) Ajari anak untuk berjabat tangan . 


\section{h. Model Pembiasaan Perkataan}

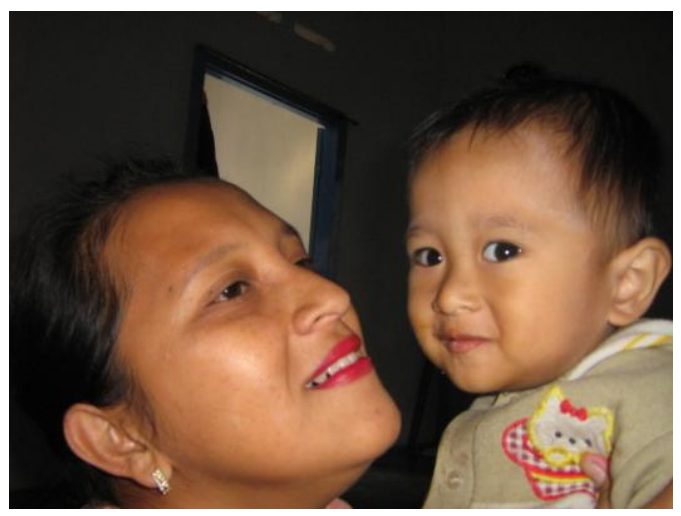

Bahasa merupakan cermin dari pribadi. Itulah sebabnya ada kata budi bahasa. Agar anak mempunyai bahasa yang mencerminkan sifat cinta dan kasih sayang, biasakan mereka mengungkapkan perasaan itu.

(1) "Allah mencintai kita, ayo kita berdoa agar Allah bertambah cinta kepada kita!"

(2) "Allah menyayangi kita, mari kita berdoa agar Allah bertambah sayang kepada kita!"

(3) "Agar Allah tetap mencintai dan menyayangi kita, Ayo kita berdoa!"

(4) Ibu sayang padamu (atau sebutkan nama anak Ibu)

(5) (Setiap akan memulai sesuatu ajarkan anak untuk membaca basmalah) Bismillaah (hirrohmaa nirrohiim)

(6) (Setiap mengakhiri sesuatu ajarkan anak untuk membaca hamdalah) Alhamdulillaah.

\section{Penutup}

Model pendidikan kecerdasan spiritual anak balita melalui pemanfaatan waktu luang ibu rumah tangga bisa dilakukan dengan berbagai model. Model itu antara lain adalah (a) contoh perbuatan, (b) nasihat, (c) permainan, (d) 
teka-teki, (e) cerita, (f) lagu, (g) pembiasaan tingkah laku, dan (h) pembiasaan perkataan. Hal yang bisa dikembangkan, antara lain, adalah cinta kasih, kejujuran, kecerdasan, keadilan, bekerja sama, perhatian, mandiri, percaya diri, atau dermawan, baik dalam hubungannya dengan Tuhan, diri sendiri, sesama manusia, maupun alam sekitar. Semoga melalui tulisan ini, ibu-ibu rumah tangga dapat memanfaatkan waktu luangnya untuk mendidik anak-anak mereka menuju manusia yang cerdas spiritual. 


\section{Pustaka Acuan}

Agustian, Ary Ginanjar. 2005. Rahasia Sukses Membangun Kecerdasan Emosi dan Spiritual, ESQ (Emotional Spiritual Quotient). Jakarta: Penerbit Arga

Prahastuti, Endang. 1998. Pola Pendidikan Anak Balita di Kawasan Rumah Sangat Sederhana (Kasus di Perumnas Sawojajar Malang). Malang: PPS IKIP

Malang: Tesis tidak diterbitkan

Tasmara, Toto. 2001. Kecerdasan Ruhaniah. Jakarta: Gema Insani

Satiadarma, Monty P. dan Waruwu, Fidelis E. 2003. Mendidik Kecerdasan. Jakarta: Pustaka Populer Obor

Sinetar Marshal, 2001 Spiritual Intelligence. Jakarta: Elex Media Komputindo

Spodek, B.Saracho.O.N. dan Davis, M.D. 1987. Foundations Of Early Chilhood Education. New Je rsey: Prentice Hall, Inc

Sukidi. 2004. Kecerdasan Spiritual. Jakarta: Gramedia

Zohar, Danah, Marshall (dalam Rahmat, Jalaluddin). 2002 Spirilual Question Memanfaatkan Kecerdasan Spirilual dalam Berpikir Integralistik dan Holistik untuk Memaknai Hidup. Bandung: Mizan. 